\title{
Electrochemical modification of individual nano-objects
}

\author{
M. Knez ${ }^{\text {a }}$, M. Sumser ${ }^{\text {b }, A . M . ~ B i t t n e r ~}{ }^{\text {a }}$, C. Wege ${ }^{\text {b }}$ H. Jeske ${ }^{\text {b }}$, S. Kooi ${ }^{\text {a }}$, \\ M. Burghard ${ }^{\mathrm{a}, *}, \mathrm{~K}$. Kern ${ }^{\text {a }}$ \\ ${ }^{a}$ Max-Planck-Institut für Festkörperforschung, Heisenbergstraße 1, 70569 Stuttgart, Germany \\ ${ }^{\mathrm{b}}$ Biologisches Institut, Universität Stuttgart, Pfaffenwaldring 57, 70550 Stuttgart, Germany
}

Received 16 July 2001; received in revised form 30 October 2001; accepted 11 November 2001

\begin{abstract}
Two examples of selective electrochemical modification of individual nanoscale objects are presented, namely the electroless metallization of a plant virus, and the coupling of substituted phenyl residues to single-wall carbon nanotubes (SWCNTs). The electroless deposition of metal was achieved selectively on the inner or outer surface of tobacco mosaic virus (TMV) particles. Covalent modification of SWCNTs, deposited on a $\mathrm{Si} / \mathrm{SiO}_{2}$ substrate, was performed successfully via reductive coupling of a 4-nitrobenzenediazonium salt in non-aqueous medium. An organic layer with a thickness of up to several nanometers could be deposited on isolated tubes and thin bundles. (C) 2002 Elsevier Science B.V. All rights reserved.
\end{abstract}

Keywords: Catalytic reduction; Deposition; Interface; Thin layer; Chemically modified electrode

\section{Introduction}

The electrochemical modification of individual molecules or supramolecular units has attracted considerable interest in recent years. In this context, electroless (no external current source) metallization of nanoscopic objects represents an attractive approach to small conductive structures due to its simplicity - only contact with a metallization bath is required. On the other hand, fine-tuning of the bath chemistry allows us to handle matter that is susceptible to damage by lithography or metal evaporation. Examples where coverage with metal clusters or layers was obtained include carbon nanotubes [1], track-etched tubes [2,3], DNA [4], microtubules (protein filaments) [5] and lipid tubules [6]. In general, electroless deposition is performed in a bath containing metal ions and a reductant. The pertaining redox reaction can proceed only on a surface that catalyzes the oxidation of the reductant. This surface can either be a noble metal or be provided by the reduction of the metal ions [7]. In the former case the noble metal has to be in contact with a

\footnotetext{
* Corresponding author. Tel.: + 49-711-689-1430; fax: +49-711689-1010.

E-mail address: m.burghard@fkf.mpg.de (M. Burghard).
}

substrate, in our case with the surface of a plant virus. This 'activation' process usually relies on tin-palladium clusters whose sizes exceed $10 \mathrm{~nm}$. For a true nanoscopic metallization we have developed a pure palladium formulation [8] that results in much finer clusters bound to organic layers. Here we show that the same principle can be applied to biological material, i.e. the tobacco mosaic virus (TMV).

Single-wall carbon nanotubes (SWCNTs) have been used as an inert electrode material in the study of the redox properties of small biomolecules or inorganic redox couples [9]. These experiments were performed with both bulk SWCNT material ('bucky paper') $[10,11]$ and individual thin SWCNT bundles [12], for example, to address the electrocatalytic behaviour [13] of the tubes. On the other hand, the insertion of cations/anions in aqueous or non-aqueous medium, associated with the reduction/oxidation of SWCNT bulk material, has been reported [14-16]. However, little is known about the electrochemical modification of the tubes themselves, in order to attach functional groups covalently to the tube's carbon lattice. Very recently, Bahr et al. reported the reductive coupling of a series of different aryl diazonium salts to bucky paper electrodes [17] consisting of small diameter SWCNTs $(d \sim 0.7 \mathrm{~nm})$. It should be noted that most of the 
above-mentioned investigations were performed on SWCNTs that were purified by oxidative treatments like refluxing in nitric acid, which are known to introduce various oxygen-containing functional groups in different amounts $[18,19]$. In the present contribution, we describe the electrochemical modification of individual, pristine SWCNTs/thin bundles (3-5 nm in height) with nitro-substituted phenyl groups by following the diazonium coupling scheme $[20,21]$. This approach was employed successfully to decorate the tubes with a layer of controllable thickness of up to several nanometers.

\section{Experimental}

Aqueous TMV suspensions were obtained from Nicotiana tabacum cv. Samsun plants infected with TMV vulgare [22,23]. For the Pd activation of TMV $100 \mu \mathrm{l}$ of the virus suspension $\left(0.2 \mathrm{mg} \mathrm{ml}^{-1}\right)$ were mixed with $100 \mu 13 \mathrm{mM} \mathrm{Na}_{2} \mathrm{PdCl}_{4}$ and adjusted to $\mathrm{pH}$ 3-5.5 with $\mathrm{HCl}$. After 5 min the suspension was centrifuged (4 min, $14000 \mathrm{~g}$ ), and the palladium-virus pellet was washed twice with $\mathrm{H}_{2} \mathrm{O}$.

\subsection{Electroless baths}

For nickel we used $12 \mathrm{~g} \quad \mathrm{NiCl}_{2} \cdot 6 \mathrm{H}_{2} \mathrm{O}+23 \mathrm{~g}$ $\mathrm{NaH}_{2} \mathrm{PO}_{2} \cdot \mathrm{H}_{2} \mathrm{O}+30 \mathrm{~g} \mathrm{Na}_{2} \mathrm{~B}_{4} \mathrm{O}_{7}+9 \mathrm{~g}$ glycine in $500 \mathrm{ml}$ $\mathrm{H}_{2} \mathrm{O}$, adjusted with $\mathrm{NaOH}$ to $\mathrm{pH} 9$. For the silver $10 \mu \mathrm{l}$ virus suspension $\left(10 \mathrm{mg} \mathrm{ml}^{-1}\right)$ was mixed with $100 \mu \mathrm{l}$ of a silver electroless bath $\left(5 \mathrm{ml} 0.2 \% \mathrm{AgNO}_{3}+4.1 \mu \mathrm{l}\right.$ $37 \% \mathrm{HCHO}$ ); after $15 \mathrm{~min}$ the suspension was dialysed against a mixture of $5 \mathrm{ml} 6 \% \mathrm{Na}_{2} \mathrm{CO}_{3}+2.7 \mu \mathrm{l} 37 \%$ $\mathrm{HCHO}+100 \mu \mathrm{l} 0.02 \% \mathrm{Na}_{2} \mathrm{~S}_{2} \mathrm{O}_{3}$ (a brown colour develops); finally the suspension was treated with a mixture of $5 \mathrm{ml} \mathrm{99 \%} \mathrm{CH}_{3} \mathrm{OH}+1 \mathrm{ml} \mathrm{99 \%} \mathrm{CH}_{3} \mathrm{COOH}+4 \mathrm{ml}$ $\mathrm{H}_{2} \mathrm{O}$. Each step was followed by dialysis against $\mathrm{H}_{2} \mathrm{O}$.

For transmission electron microscopy (TEM) we employed a Zeiss EM $10(60 \mathrm{kV})$ and a Philips CM 200 $(200 \mathrm{kV})$, and for atomic force microscopy (AFM) we used a Thermomicroscopes M5 Autoprobe equipped with PSI Ultralever cantilevers in the intermittent contact mode.

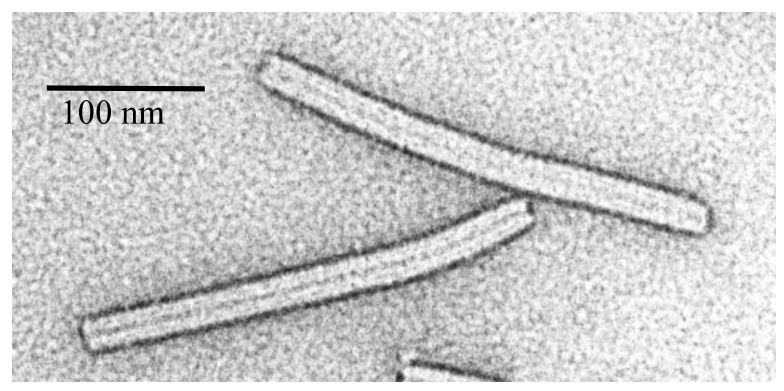

Fig. 1. TEM image of two TMVs after contrasting with $\mathrm{UO}_{2}\left(\mathrm{CH}_{3} \mathrm{COO}\right)_{2}$. The uranyl ions appear black. They outline the outer surface (thick black lining) and the inner channel (faint line).

\subsection{Nanotube deposition}

SWCNT material produced by the arc discharge method (Carbolex ${ }^{\circledR}$, Lexington, USA) was dispersed in an aqueous (1 wt.\%) lithium lauryl sulphate solution and purified via centrifugation. The resulting suspension was deposited on a highly doped $\mathrm{Si}$ wafer substrate with a $100 \mathrm{~nm}$ thick thermally grown $\mathrm{SiO}_{2}$ layer, which was treated before for $2 \mathrm{~min}$ in an $1 \mathrm{mM}$ aqueous solution of 3-(aminopropyl)-triethoxysilane. After 30 min of adsorption time, the wafer surface was blown dry with a stream of argon, rinsed in ultra-pure water and dried again. A $1 \mathrm{~nm}$ titanium adhesion layer and 15 $\mathrm{nm}$ of gold-palladium were evaporated during the standard electron beam lithography procedure used to define electrode patterns on top of the randomly deposited SWCNTs. The titanium layer is crucial to prevent the electrodes from peeling of the $\mathrm{SiO}_{2}$ surface when a potential is applied to them in electrolyte solution. To control the potential applied in the electrochemical experiments, a Solartron 1285 potentiostat was employed. AFM images were taken with a Digital Instruments Nanoscope IIIA microscope operated in tapping mode, using commercial silicon cantilevers.

\section{Electroless metal deposition onto and into tobacco mosaic viruses}

TMV is a $300 \mathrm{~nm}$ long supramolecular tube comprised of a RNA strand and 2130 identical coat proteins. The inner channel (4 $\mathrm{nm}$ diameter) as well as the outer protein surface provide substrates for adsorptive and electroless processes.

Fig. 1 shows a TEM image of TMV after treatment with $\mathrm{UO}_{2}\left(\mathrm{CH}_{3} \mathrm{COO}\right)_{2}$ for better contrast. The uranyl ions appear black; they bind to the protein as well as RNA and thus aid in visualizing the inner channel and outer surface. Albeit the dispersion of the ions is very good we cannot use this method for electroless deposition since the uranyl ions have a very negative Nernst potential; during their reduction the proteins and the RNA would be damaged.

We developed a special variant of the $\mathrm{Pd}^{2+}$ activation procedure used for electroless deposition. The rather low $\mathrm{pH}(3-5.5)$, but especially the exclusive use of freshly dissolved palladate ensure that very little polycondensation occurs [8]; otherwise the unwanted rather large poly(hydroxo-aquo-palladium(II)) would form. After centrifugation and washing the viruses are resuspended in water or in an electroless deposition bath.

Fig. 2 presents two microscopic images of viruses after treatment with an electroless nickel bath depositing $\mathrm{Ni}(\mathrm{P})$. From the general appearance of the TEM micrograph (Fig. 2A) and the intermittent contact 

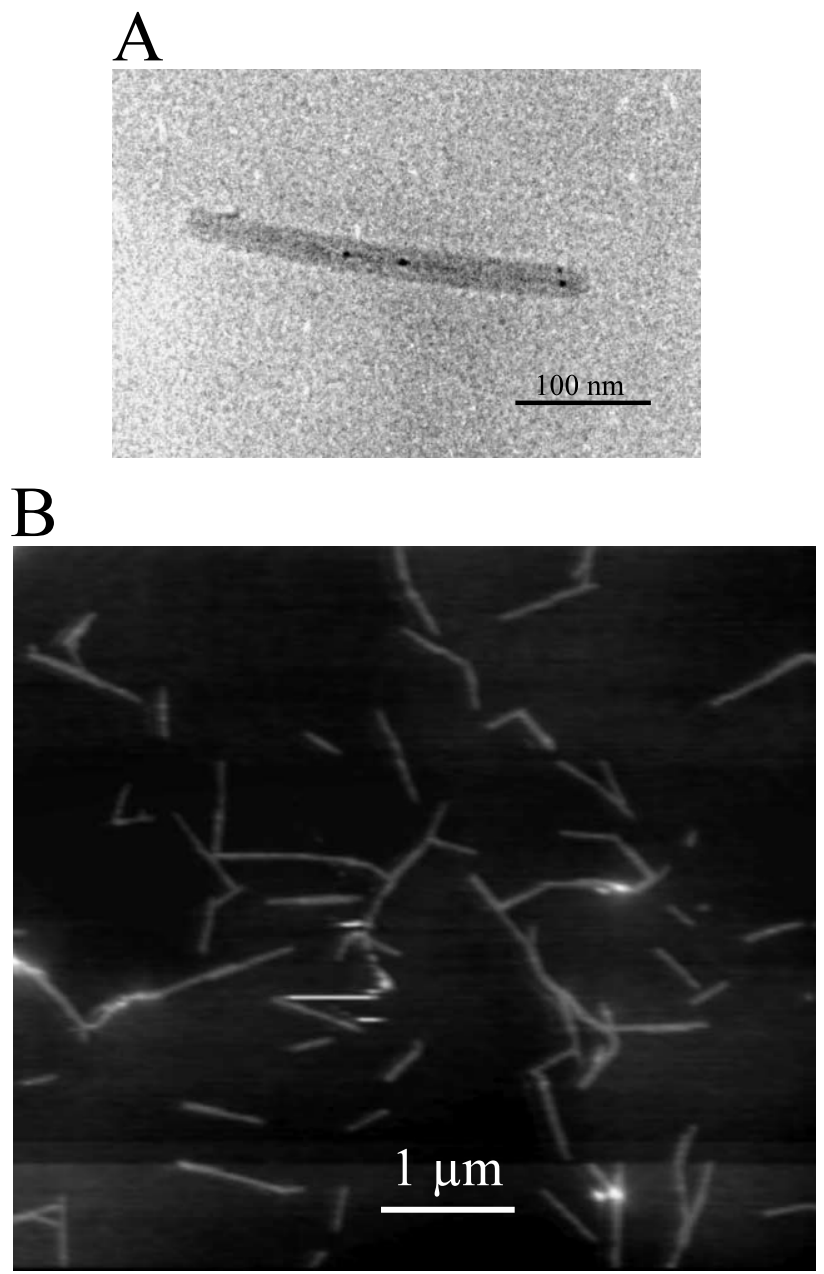

Fig. 2. (A) TEM image of TMV after activation with $\mathrm{Pd}^{2+}$ and electroless deposition of $\mathrm{Ni}(\mathrm{P})$ from a $\mathrm{H}_{2} \mathrm{PO}_{2}^{-}$bath; (B) intermittent contact AFM image of TMV after the same treatment and adsorption on mica.

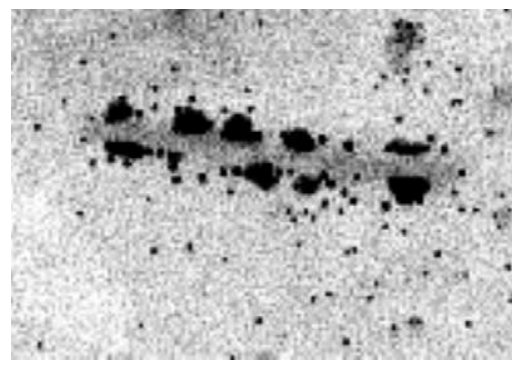

Fig. 3. TEM image of TMV after adsorption of $\mathrm{Ag}^{+}$and reduction with formaldehyde.

AFM image (Fig. 2B), we infer that the protein structure of the virus has been preserved, despite the presence of a reducing substance $\left(\mathrm{H}_{2} \mathrm{PO}_{2}^{-}\right)$. Note that the $\mathrm{pH}$ of the bath is compatible with the stability range of TMV ( $\sim 2.5$ to $\sim 9.0)$. The majority of the viruses is metallized. Surprisingly the Ni-rich black spots are in almost all metallized TMVs found in the channel re- gion. In the AFM image some of the viruses show bright spots that correspond to locally increased heights. The presence of black spots in the TEM image and of increased heights in the AFM image, both only observed after the nickel deposition, support an interpretation as $\mathrm{Ni}(\mathrm{P})$ clusters. Hence the $\mathrm{Pd}$ activation and the $\mathrm{Ni}(\mathrm{P})$ deposition on the $\mathrm{Pd}$ are rather facile inside the channel. This suggests that the RNA, and not the proteins, forms a complex with $\mathrm{Pd}^{2+}$. After the reduction to Pd clusters, at least some clusters remain inside the channel.

Fig. 3 shows a TMV after the three-step silver treatment (see Section 2). The presence of the black silver clusters proves that silver is its own activator. All TMVs are metallized. However, $\mathrm{Ag}^{+}$appears to favour binding to the exterior surface, and silver is never deposited inside the channel. A basis of an interpretation for the selective metallization is the presence of chemical groups on the outer surface that favour binding to $\mathrm{Ag}^{+}$. The most likely candidates would be the outermost amino acids that are terminated by a carboxylate group. The latter have a high affinity for $\mathrm{Ag}^{+}$.

A decisive factor for the metallization mechanisms should be kinetic limitations. For example, the single thiol group (per protein), a cystein moiety, could easily bind $\mathrm{Pd}^{2+}$, but it is located deep inside the protein, while the RNA is quite accessible - only a rather flexible loop of several amino acids is located between the RNA and the central channel. We generally expect that those metal ions that form complexes with carboxylic acids (e.g. $\mathrm{Ag}^{+}$) bind in a fast reaction to the terminal carboxylic acid group at the outer TMV surface. Whenever this reaction is slow, metal complexes such as $\mathrm{PdCl}_{4-n}\left(\mathrm{H}_{2} \mathrm{O}\right)_{n}^{n-2}$ can diffuse into the central channel where RNA and protein offer a range of nitrogen-containing ligands that can substitute $\mathrm{Cl}^{-}$and $\mathrm{H}_{2} \mathrm{O}$. Metal ions like $\mathrm{Pd}^{2+}$ are weakly bound to the outside and can thus be removed by washing with water.

\section{Electrochemical modification of individual nanotubes/thin bundles via reductive coupling of diazonium salts}

The reduction of a 4-nitrobenzenediazonium salt was used to attach 4-nitrophenyl groups covalently to SWCNTs deposited on a $\mathrm{Si} / \mathrm{SiO}_{2}$ substrate. The reduction of the 4-nitrobenzenediazonium cation, as illustrated by the reaction scheme in Fig. 4, produces a radical species at or near the SWCNT surface. The radical can then attack the tubes, forming a covalent bond to the carbon lattice.

The electrochemical modification is carried out in a mini-electrochemical cell with platinum counter and (pseudo-)reference electrodes. A probe needle is used to make contact with one of the $\mathrm{Au} / \mathrm{Pd}$ bonding pads on 
the substrate, and allows the application of an electric potential to the electrode and therefore to any SWCNTs underneath the electrode. Fig. 5A displays an
AFM image of a typical electrode structure used, showing several SWCNTs/thin bundles contacted below the four electrode lines. The redox behaviour of 4-nitroben-

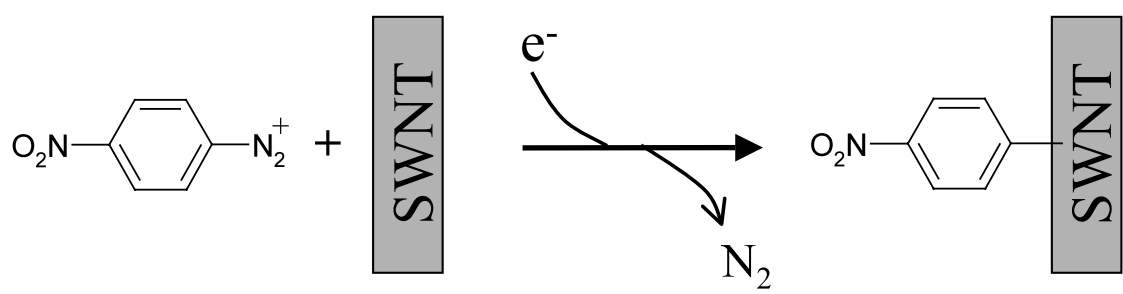

Fig. 4. Reaction scheme for diazonium salt coupling to functionalize single-wall carbon nanotubes.

A

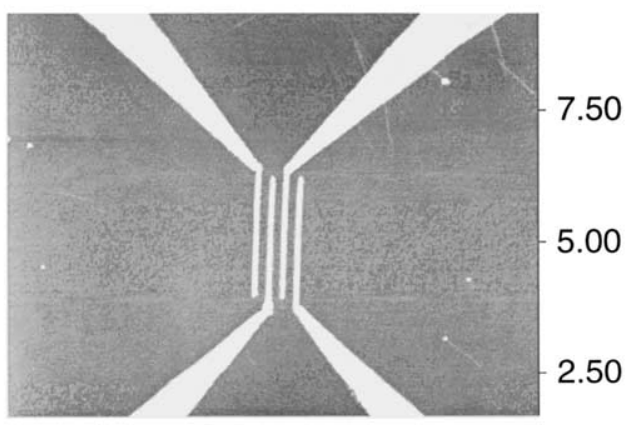

0

$10.00 \mu \mathrm{m}$
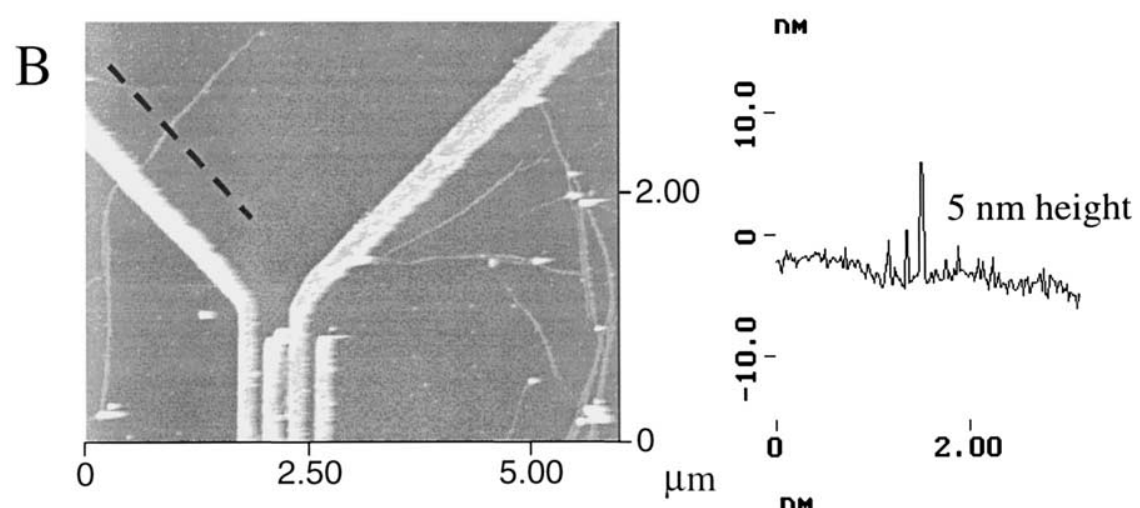

$\mathrm{C}$
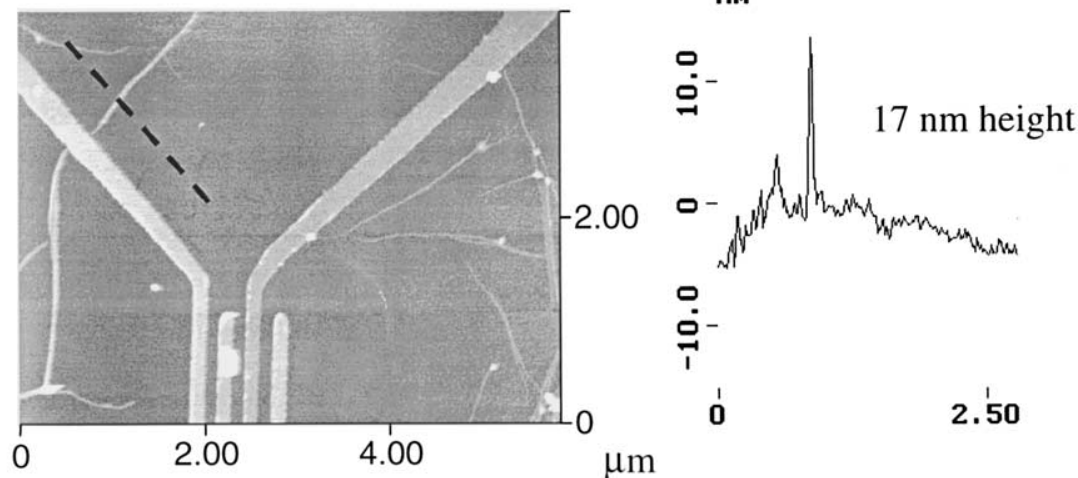

$$
\stackrel{\circ}{\dot{1}}-
$$

' 2.150

Fig. 5. AFM images of (A) a typical electrode structure with contacted tubes used in the electrochemical modification experiments; (B) contacted SWCNTs before reductive coupling, and (C) the same SWCNTs after electrochemical modification with 4-nitrophenyl groups by application of $-1.3 \mathrm{~V}$ vs. Pt for $30 \mathrm{~s}$ to the left side electrode. The portions of the SWCNTs not covered by the $\mathrm{Au} / \mathrm{Pd}$ electrode line are noticeably thicker due to the coating. On the right side of (B and C), the AFM height profile (along the broken line) of the upper thin bundle is displayed. 
zenediazonium tetrafluoroborate was studied in a bulk electrochemical cell with $N, N$-dimethylformamide (DMF) as the solvent and tetrabutylammonium-tetrafluoroborate as the electrolyte, revealing an irreversible reduction wave characteristic of aryl radical formation at $-1.3 \mathrm{~V}$. The same potential is applied in the mini-electrochemical cell for a time long enough to observe changes in the size of the modified SWCNTs by AFM. This requires a growth of at least several layers of the attached molecules which typically takes longer than 30 s. The layer growth is associated with the polymerization of phenyl units. A similar mechanism leading to azo-polymer multilayer films has been reported previously [24] for highly oriented pyrolytic graphite (HOPG). As a representative example, Fig. 5B and $\mathrm{C}$ show AFM images of the same SWCNTs before and after electrochemical modification, respectively. The portions of the SWCNTs underneath the left hand side $\mathrm{Au} / \mathrm{Pd}$ electrode remain unmodified, and therefore retain their original size, while 4-nitrophenyl groups grafted onto the exposed portions of the SWCNTs account for the observed increase in thickness. From the AFM height profiles displayed on the right side of Fig. 5B and $\mathrm{C}$ a thickness increase of $\sim 12 \mathrm{~nm}$ is found after modification of the bundle on the top side. It is noteworthy that no layer formation is observed on the tubes contacted by the right hand side electrode to which no potential was applied. In general, the degree of modification is found to depend on the concentration of the diazonium salt, the duration of the applied potential, and the magnitude of the applied potential. The presence of 4-nitrophenyl residues on the SWNTs could be confirmed by scanning Auger microscopy on the coating observed in the AFM images.

\section{Conclusions}

We have demonstrated both electroless and galvanic modification of nanoscale objects. While these techniques are well known for modification of bulk materials, the examples herein have demonstrated their applicability to individual molecules/supramolecular structures. For the electroless deposition, we have shown that it is possible to metallize a biological virus template in a controlled manner. Depending on the metallization conditions we can selectively target the outer or inner surface of the tube-like TMV. The local nanochemistry, i.e. certain amino acid moieties and the RNA of the virus, determines the bond strength to a transition metal cation. Upon reduction, metal clusters form. They cannot be removed although their bond strength to the template is lower than that of the metal ions. Linear arrays of clusters are thus obtained on the basis of wet chemistry, i.e. without the need of lithography. We have also demonstrated the ability to modify electrochemically individual objects (SWCNTs), deposited on a solid support, through a diazonium aryl radical coupling mechanism. The wide range of different diazonium salts available opens the possibility of producing modified SWCNTs with tailored surface properties useful for chemical and biological applications.

\section{References}

[1] J. Li, M. Moskovits, T.L. Haslett, Chem. Mater. 10 (1998) 1963.

[2] K.B. Jirage, J.C. Hulteen, C.R. Martin, Anal. Chem. 71 (1999) 4913.

[3] B. Brunetti, P. Ugo, L.M. Moretto, C.R. Martin, J. Electroanal. Chem. 491 (2000) 166

[4] J. Richter, R. Seidel, R. Kirsch, M. Mertig, W. Pompe, J. Plaschke, H.K. Schackert, Adv. Mater. 12 (2000) 507.

[5] R. Kirsch, M. Mertig, W. Pompe, R. Wahl, G. Sadowski, K.J. Böhm, E. Unger, Thin Solid Films 305 (1997) 248.

[6] M. Markovitz, S. Baral, S. Brandow, A. Singh, Thin Solid Films 224 (1993) 242

[7] G.O. Mallory, J.B. Hajdu (Eds.), Electroless Plating: Fundamentals and Applications, AESF, Orlando, 1990.

[8] H. Kind, A.M. Bittner, O. Cavalleri, K. Kern, T. Greber, J. Phys. Chem. B 102 (1998) 7582.

[9] J.M. Nugent, K.S.V. Santhanam, A. Rubio, P.M. Ajayan, Nano Lett. 1 (2001) 87.

[10] J.J. Davis, R.J. Coles, A.O. Hill, J. Electroanal. Chem. 440 (1997) 279.

[11] P.J. Britto, K.S.V. Santhanam, P.M. Ajayan, Bioelectrochem. Bioeng. 41 (1996) 121

[12] J.K. Campbell, L. Sun, R.M. Crooks, J. Am. Chem. Soc. 121 (1999) 3779.

[13] P.J. Britto, K.S.V. Santhanam, A. Rubio, J.A. Alonso, P.M. Ajayan, Adv. Mater. 11 (1999) 154.

[14] J.N. Barisci, G.G. Wallace, R.H. Baughman, Electrochim. Acta 46 (2000) 509.

[15] J.N. Barisci, G.G. Wallace, R.H. Baughman, J. Electroanal. Chem. 488 (2000) 92.

[16] G.U. Sumanasekera, J.L. Allen, S.L. Fang, A.L. Loper, A.M. Rao, P.C. Eklund, J. Phys. Chem. B 103 (1999) 4292.

[17] J.L. Bahr, J. Yang, D.V. Kosynkin, M.J. Bronikowski, R.E. Smalley, J.M. Tour, J. Am. Chem. Soc. 123 (2001) 6536.

[18] A.C. Dillon, K.M. Jones, T.A. Bekkedahl, C.H. Kiang, D.S. Bethune, M.J. Heben, Nature 386 (1997) 377.

[19] I.W. Chiang, B.E. Brinson, R.E. Smalley, J.L. Margrave, R.H. Hauge, J. Phys. Chem. B 105 (2001) 1157.

[20] M. Delamar, R. Hitmi, J. Pinson, J.-M. Savéant, J. Am. Chem. Soc. 114 (1992) 5883.

[21] B. Ortiz, C. Saby, G.Y. Champagne, D. Bélanger, J. Electroanal. Chem. 455 (1998) 75.

[22] M. Sumser, Diploma Thesis, Universität Stuttgart, 2001.

[23] M. Knez, M. Sumser, A.M. Bittner, C. Wege, H. Jeske, T.P. Martin, K. Kern, in preparation.

[24] J.K. Kariuki, M.T. McDermott, Langmuir 15 (1999) 6534. 